\title{
Synthesis of Polyfluorene-Polytriarylamine Block Copolymer with Emitting Part at Junction Point for Light Emitting Applications
}

\author{
Mehdi Jahanfar, Kenta Suwa, Kousuke Tsuchiya, Kenji Ogino* \\ Graduate School of Bio-Applications and Systems Engineering, \\ Tokyo University of Agriculture and Technology, Tokyo, Japan \\ Email: ${ }^{*}$ kogino@cc.tuat.ac.jp
}

Received January 22, 2013; revised February 22, 2013; accepted March 3, 2013

Copyright (C) 2013 Mehdi Jahanfar et al. This is an open access article distributed under the Creative Commons Attribution License, which permits unrestricted use, distribution, and reproduction in any medium, provided the original work is properly cited.

\begin{abstract}
A block copolymer consisting of polyfluorene (PF) and polytriarylamine (PTAA) functionalized with green emitting phenoxazine moiety at the junction point of two blocks was designed and prepared for electroluminescent application. PF homopolymer was synthesized by Suzuki coupling polymerization, and was reacted with brominated phenoxazine. In the presence of the resulting PF functionalized with phenoxazine, C-N coupling polymerization of 4-(4'-bromophenyl)-4"'-butyldiphenylamine was carried out to afford a triblock copolymer, PTAA-phenoxazine-PF-phenoxazinePTAA (PF-Ph-PTAA). Two types of random copolymers were also synthesized with fluorene and phenoxazine (PF2) by Suzuki coupling polymerization for comparison. All the polymers were soluble in common organic solvents and readily formed thin films by a solution processing. Prepared polymers exhibited similar UV absorption and PL emission in chloroform solutions. In a film state, the existence of phenoxazine unit drastically changed PL spectra. Although the content of phenoxazine unit in PF-Ph-PTAA was relatively high (13 mol\%), it showed similar PL spectrum to that of PF2(phenoxazine content, $0.2 \mathrm{~mol} \%$ ) indicating that phenoxazine unit is isolated in single polymer chain nevertheless the high content. EL device based on PF-Ph-PTAA showed green-emission, suggesting that emission sites predominantly located in the vicinity of phenoxazine moiety because of its shallow HOMO level.
\end{abstract}

Keywords: Polyfluorene; Polytriarylamine; Block Copolymer; Junction Point; Polymer Light-Emitting Diode

\section{Introduction}

Polymer light-emitting diodes (PLEDs) have attracted much scientific and technological research interest since their first discovery in 1990 [1]. Utilization of electroluminescent polymeric materials shows several advantages over organic small molecules for use in PLEDs: better processability, and high flexibility [2]. Furthermore, inexpensive wet-processes such as spin-coating and ink-jet can be applied for the fabrication of PLED devices, which is essential in order to apply PLEDs to display and lighting technologies.

Unfortunately, it is generally recognized that polymeric devices show lower performance (efficiency, life time) compared with devices fabricated with a vacuum process based on low-molecular weight materials. Low efficiency in polymeric devices is partially due to difficulty in fabricating the devices with a layered-structure.

\footnotetext{
"Corresponding author.
}

To overcome the drawbacks, a breakthrough is necessary from the point of the molecular design and the control the morphology in the active layer. We have showed the advantage of block copolymers consisting of hole and electron transporting blocks as the host materials in phosphorescent devices [3-5]. Block copolymers were prepared via a nitroxide mediated living radical polymerization.

Block copolymers assemble into micro- or nano-phase separated structures with various domain shapes such as lamella, cylinder, or sphere. Exploiting nanostructures of block copolymers with appropriate designs can improve performance of applications due to allocation of functionality to each domain [6]. The other groups also reported several block copolymers for PLED applications $[7,8]$.

More recently Tan et al. synthesized the different type of block copolymers for EL applications via the Suzuki coupling polymerization followed by the $\mathrm{C}-\mathrm{N}$ coupling 
polymerization $[9,10]$, which consisted of light emitting and electron transporting polyfluorene (PF) unit and hole transporting polytriarylamine (PTAA) unit. It was revealed that the introduction of PTAA increased emission efficiencies compared with PF homopolymer. This is due to the facile hole injection from the anode and/or the efficient electron block by PTAA moieties, which are located in the vicinity of the PEDOT/PSS coated on the anode through the hydrogen bonding of trioxyethylene group with PSS [10].

Here we proposed the novel methodology for the increase the efficiency in PLED. That is the novel molecular design of full functional polymers, which are block copolymers consisting of hole transporting unit and electron transporting unit with emitting moiety at the junction point. In the previous devices utilizing block copolymers as host polymers, emitting materials are low molecular weight phosphorescent dyes dispersed in host materials. In this case, emitting parts are randomly distributed in the active layer. Emission process is resulted from the recombination of holes and electrons, followed by the energy transfer from recombination centers to emitting moieties and/or the charge trap predominately occurred at the emitting sites. Therefore if the emitting parts are located in the vicinity of the interface between hole and electron transporting domains, more efficient energy transfer and carrier trap are anticipated. In order to attain the situation, a new molecular design is proposed. Target polymers are block copolymers consisting of hole transporting unit and electron transporting unit with emitting moiety at the junction point. If an ideal phase separation occurs, the emitting moiety exists at the interface between both domains.

In this study, the synthetic strategy we established for PF-b-PTAA (Suzuki coupling followed by C-N coupling polymerization) is modified to prepare a block copolymer consisting of PF and PTAA functionalized with green emitting phenoxazine moiety at the junction point of two blocks. Phenoxazine derivatives are known as a emitting dye $[11,12]$, and have been utilized as the component of EL copolymers [13,14]. EL characteristics were preliminarily investigated for the comparison with random copolymer.

\section{Experimental}

\subsection{Materials}

Figure 1 illustrates the synthetic route of targeted polymers. n-Butylphenylphenoxazine (1) [14], 2,7-dibromo9-(4-methylphenyl)-9-(4-octylphenyl)-fluorene (4) [9], 2,7-bis(4,4,5,5-tetramethyl-1,3,2-dioxaborolan-2-yl)-9(4-methylphenyl)-9-(4-octylphenyl)-fluorene (5) [9], 4-(4'-bromophenyl)-4"-butyl-diphenylamine (6) [15] were synthesized according to reported procedures. All reagents and solvents were used without further purification unless stated otherwise. Tetrahydrofuran (THF) was distilled over sodium and benzophenone, and stored under nitrogen atmosphere. Toluene was distilled over calcium hydrine, and stored under nitrogen atmosphere. The other regents and solvents were obtained commercially
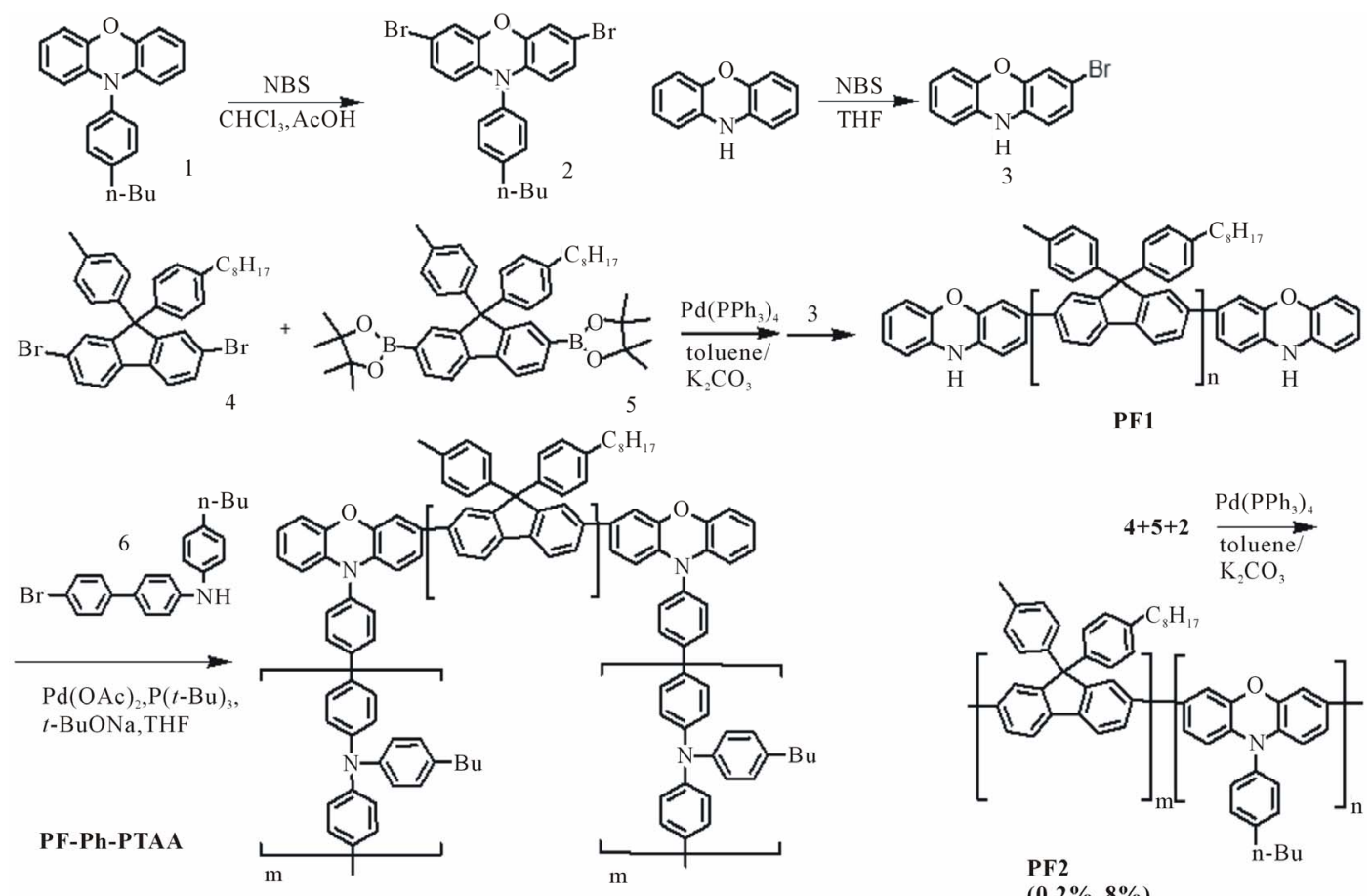

$\mathrm{C}_{8} \mathrm{H}_{17}$

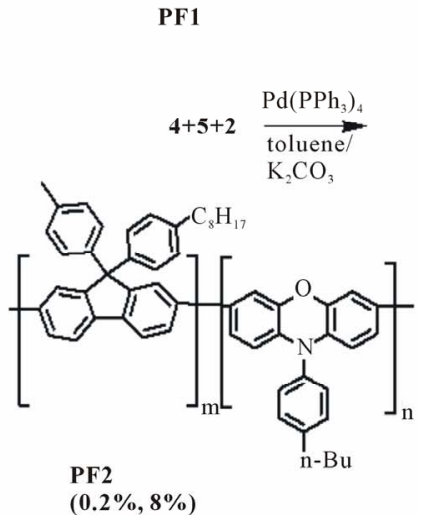

Figure 1. Synthetic scheme of block and random copolymers. 
and were used as received.

\subsection{Characterization}

${ }^{1} \mathrm{H}$ and ${ }^{13} \mathrm{C}$ NMR spectra were obtained on a JEOL ALPHA300 instrument at $25^{\circ} \mathrm{C}$ at 300 and $75 \mathrm{MHz}$, respectively. Deuterated chloroform was used as a solvent with tetramethylsilane as an internal standard. Number- and weight-average molecular weights $\left(M_{n}\right.$ and $\left.M_{w}\right)$ and polydispersity index (PDI) were determined by gel permeation chromatography (GPC) analysis calibrated by standard polystyrene samples with a JASCO RI-2031 detector eluted with chloroform at a flow rate of $0.5 \mathrm{ml} / \mathrm{min}$ at room temperature. Differential scanning calorimetry (DSC) analysis was performed on a Rigaku DSC-8230 under nitrogen atmosphere at heating and cooling rates of 10 ${ }^{\circ} \mathrm{C} / \mathrm{min}$. UV-vis absorption spectra were obtained on a JASCO V-570 spectrophotometer and fluorescence spectra were obtained with JASCO FP-6500 spectrophotometer with an excitation at $380 \mathrm{~nm}$. Cyclic voltammetry (CV) was conducted on a Niko Keisoku Model NPGFZ2501-A potentiogalvanostat. All measurements were carried out at room temperature in a typical three-electrode cell with a working electrode (glassy carbon electrode), a reference electrode $(\mathrm{Ag} / \mathrm{AgCl})$, and a counter electrode (Pt wire) at a scanning rate of $0.1 \mathrm{~V} / \mathrm{s}$. In all measurements, acetonitrile and tetrabutylammonium tetrafluorocarbonate $\left(\mathrm{Bu}_{4} \mathrm{NBF}_{4}\right)(0.1 \mathrm{M})$ were used as a solvent and a su-pporting electrolyte, respectively.

\subsection{Synthesis of 3,7-Dibromo-N-butylphenyl- phenoxazine (2)}

To a $100 \mathrm{~mL}$ flask equipped with a stopcock and a condenser were placed N-butylphenylphenoxazine (1) (0.44 g, $1.39 \mathrm{mmol})$, chloroform $(20 \mathrm{~mL})$, acetic acid $(20 \mathrm{~mL})$, N-bromosuccinimide (NBS) $(0.52 \mathrm{~g}, 2.91 \mathrm{mmol})$ in $0^{\circ} \mathrm{C}$, and the mixture was stirred for $10 \mathrm{~h}$. After the reaction the solution extracted with chloroform, and organic layer washed with water and dried with $\mathrm{MgSO}_{4}$. After chloroform was removed by a rotary evaporator, the crude product was purified by recrystallization with hexane. Light yellow solid was obtained. The yield was $0.49 \mathrm{~g}(75 \%)$. ${ }^{1} \mathrm{H}$ NMR (300 MHz, $\left.\mathrm{CDCl}_{3}\right) \delta(\mathrm{ppm}): 0.95(\mathrm{t}, 3 \mathrm{H}), 1.4$ $(\mathrm{m}, 2 \mathrm{H}), 1.70(\mathrm{~m}, 2 \mathrm{H}), 2.75(\mathrm{t}, 2 \mathrm{H}), 5.68(\mathrm{~d}, 2 \mathrm{H}), 5.75(\mathrm{~d}$, $2 \mathrm{H}), 6.79(\mathrm{~s}, 2 \mathrm{H}), 7.16(\mathrm{~d}, 2 \mathrm{H}), 7.38(\mathrm{~d}, 2 \mathrm{H}) .{ }^{13} \mathrm{C} \mathrm{NMR}$ $\left(75 \mathrm{MHz}, \mathrm{CDCl}_{3}\right) \delta(\mathrm{ppm}): 14.0,22.4,33.5,35.4,112.6$, $114.4,118.5,126.2,129.9,131.2,133.4,135.4,143.9$, 144.1 .

\subsection{Synthesis of 3-Bromophenoxazine (3)}

To a $50 \mathrm{~mL}$ flask equipped with a stopcock were placed phenoxazine (1.00 g, $5.50 \mathrm{mmol})$ and distilled THF (20 $\mathrm{mL})$. THF solution $(15 \mathrm{~mL})$ of NBS $(0.97 \mathrm{~g}, 5.5 \mathrm{mmol})$ was added dropwise to the mixture and stirred for $1 \mathrm{~h}$.
After the filtration and the evaporation of THF, the product was resolved in ethyl acetate and washed with water 3 times. After dried with $\mathrm{MgSO}_{4}$, and solvent was removed with a rotary-evaporator. The crude product was purified by column chromatography on silica gel with hexane:ethyl acetate $=1: 1$ as an eluent. The yield was $0.62 \mathrm{~g}(42 \%) .{ }^{1} \mathrm{H}$ NMR (300 MHz, $\left.\mathrm{CDCl}_{3}\right) \delta(\mathrm{ppm}): 6.66$ - $6.81(\mathrm{~m}, 7 \mathrm{H})$

\subsection{Synthesis of PF-Ran-PPh (PF2, 0.2\%)}

To a $10 \mathrm{~mL}$ flask equipped with a stopcock and a condenser were placed 4 (0.499 g, $0.143 \mathrm{mmol}), 5(0.500 \mathrm{~g}$, $0.143 \mathrm{mmol}), 2$ (0.001 g, $0.00028 \mathrm{mmol}), \mathrm{Pd}\left(\mathrm{PPh}_{3}\right)_{4}(1$ $\mathrm{mol} \%), \mathrm{K}_{2} \mathrm{CO}_{3}(2 \mathrm{M}, 2 \mathrm{~mL})$ and toluene $(3 \mathrm{~mL})$ under nitrogen atmosphere. The mixture was heated up to $90^{\circ} \mathrm{C}$ for $24 \mathrm{~h}$. After the reaction the product was extracted by chloroform and washed with water and the organic layer was dried with $\mathrm{MgSO}_{4}$. Solvent was removed with a rotary-evaporator. The crude product was purified by reprecipitation into methanol and Soxhlet extraction with acetone. The yield was $0.126 \mathrm{~g}(97 \%)$. PF2 with $8 \mathrm{~mol} \%$ of 2 was synthesized with a similar manner (98\%).

\subsection{Synthesis of PF with Phenoxazine Moieties at Chain End (PF1)}

To a $20 \mathrm{~mL}$ three-necked round-bottom flask equipped with a stopcock and a condenser were added 4 (0.166 g, $0.2757 \mathrm{mmol}), 5$ (0.226 g, $0.323 \mathrm{mmol}), \mathrm{Pd}\left(\mathrm{PPh}_{3}\right)_{4}(3.46$ $\mathrm{mg}, 0.003 \mathrm{mmol}, 0.5 \mathrm{~mol} \%), \mathrm{K}_{2} \mathrm{CO}_{3}(2 \mathrm{M}, 2 \mathrm{~mL})$, and toluene $(4 \mathrm{~mL})$ under nitrogen atmosphere, and the mixture was refluxed for $48 \mathrm{~h}$. Then, $3(0.078 \mathrm{~g}, 0.3 \mathrm{mmol})$ was added and the reflux was continued for $12 \mathrm{~h}$. After the reaction the product was extracted with chloroform, and washed with salt $\mathrm{NaCl}$ and water. Then the organic layer was dried with $\mathrm{MgSO}_{4}$. After the removal of the solvents, the product was obtained by precipitation into methanol. The yield was $0.20 \mathrm{~g}(79 \%) .{ }^{1} \mathrm{H}$ NMR $(300$ $\left.\mathrm{MHz} \mathrm{CDCl}_{3}\right) \delta(\mathrm{ppm}): 0.83-0.88(\mathrm{~m}, 3 \mathrm{H}), 1.24-1.28$ $(\mathrm{m}, 10 \mathrm{H}), 1.50-1.61(\mathrm{~m}, 2 \mathrm{H}), 2.19-2.34(\mathrm{~m}, 3 \mathrm{H}), 2.51$ - $2.56(\mathrm{~m}, 2 \mathrm{H}), 6.63$ - $6.67(\mathrm{~m}, 14 \mathrm{H}), 7.02$ - $7.18(\mathrm{~m}, 8 \mathrm{H})$, $7.41-7.65(\mathrm{~m}, 4 \mathrm{H}), 7.67$ - $7.81(\mathrm{~m}, 2 \mathrm{H})$.

\subsection{Synthesis of Block Copolymer with Phenoxazine Moiety at the Junction (PF-Ph-PTAA)}

To a $10 \mathrm{~mL}$ two-necked round-bottom flask equipped with a stopcock and a condenser were added PF1 (0.131 $\mathrm{g}, 0.01 \mathrm{mmol}$ of the terminal $), 8(0.114 \mathrm{~g}, 0.3 \mathrm{mmol})$, $\mathrm{P}(t-\mathrm{Bu})_{3}(7.5 \mu \mathrm{L}, 0.01 \mathrm{mmol}), \mathrm{Pd}(\mathrm{OAc})_{2}(0.0014 \mathrm{~g}, 0.006$ $\mathrm{mmol}), t$-BuONa $(0.032 \mathrm{~g}, 0.33 \mathrm{mmol})$, and THF $(3 \mathrm{~mL})$ under nitrogen atmosphere and the mixture was stirred under reflux for $24 \mathrm{~h}$. After removing the solvent by a rotary evaporator, the product was obtained by precipita- 
tion into methanol and acetone. The yield was $0.191 \mathrm{~g}$ $(60 \%)$.

\subsection{Device Fabrication}

Perior to preparation of device, a glass slide with indium tin oxide (ITO) patterns was washed by an alkaline cleaner under sonication and rinsed with deionized water. The substrate was subsequently washed by 2-propanol under sonication, and rinsed with clean 2-propanol, and dried with nitrogen. PEDOT:PSS with $30 \mathrm{~nm}$ of thickness was spin-coated on the substrate at $2500 \mathrm{rpm}$ for 30 $\mathrm{s}$ from the dispersion in water filtered by $0.2 \mu \mathrm{m}$ of membrane filter followed by annealing at $200^{\circ} \mathrm{C}$ for $1 \mathrm{~h}$. Polymer layer was laminated on PEDOT:PSS by spincoating at $500 \mathrm{rpm}$ for $30 \mathrm{~s}$ from chlorobenzene solution (12 $\mathrm{mg} / \mathrm{mL}$ ) filtered by $0.45 \mu \mathrm{m}$ of membrane filter, and annealed at $120^{\circ} \mathrm{C}$ for $1 \mathrm{~h}$ under nitrogen atmosphere. On the polymer, 2,9-dimethyl-4,7-diphenyl-1,10-phenanthroline (BCP) with $50 \mathrm{~nm}$ thickness was deposited by thermally evaporation in carbon pot at $240^{\circ} \mathrm{C}$ under vacuum with a rate of $1.5 \AA / \mathrm{s}$. As a cathode, lithium fluoride with $0.5 \mathrm{~nm}$ of thickness followed by a Al with $100 \mathrm{~nm}$ of thickness was deposited on the organic layer with a rate of $0.1 \AA / \mathrm{s}$ and a rate of $4.5 \AA / \mathrm{s}$ using tantalum and tungsten boats, respectively. Finally the polymer device was set into a metal can with barium oxide as a drying agent under a nitrogen atmosphere, and passivated with an epoxy resin (XNR 5570-B1, Nagase Chemtex Corporation) irradiated by UV light.

\section{Results and Discussion}

\subsection{Synthesis}

In order to prepare the PF homopolymer with phenoxadine moieties (PF1 in Figure 1), Suzuki coupling polymerization of $\mathbf{4}$ and $\mathbf{5}$ in non-stoichiometric conditions $(4 / 5=0.85 / 1.0)$ was carried out resulting in an end-functional polymer with boronic ester moieties, followed by the reaction with monobrominated phenoxazine. The successful introduction of phenoxazine moieties was confirmed by ${ }^{1} \mathrm{H}$ NMR spectrum. As shown in Figure 2(a), signals for phenoxazine protons appeared around $6.6 \mathrm{ppm}$. In order to obtain a target block copolymer (PF-Ph-PTAA) consisting of PF and PTAA functionalized with green emitting phenoxazine moiety at the junction point of two blocks, $\mathrm{C}-\mathrm{N}$ coupling polymerization of $\mathbf{6}$ was conducted in the presence of PF1 using palladium acetate and tri(tert-butyl) phosphine ligand, and tert-butoxide as a base in THF for $24 \mathrm{~h}$ in the similar manner we reported [9,15]. As shown in Figure 2(b), two types of methyl signals around $0.85 \mathrm{ppm}$, and $\mathrm{N}-\mathrm{H}$ signal from polymer ends $(5.7 \mathrm{ppm})$ were observed indicating the introduction of TAA unit as expected.

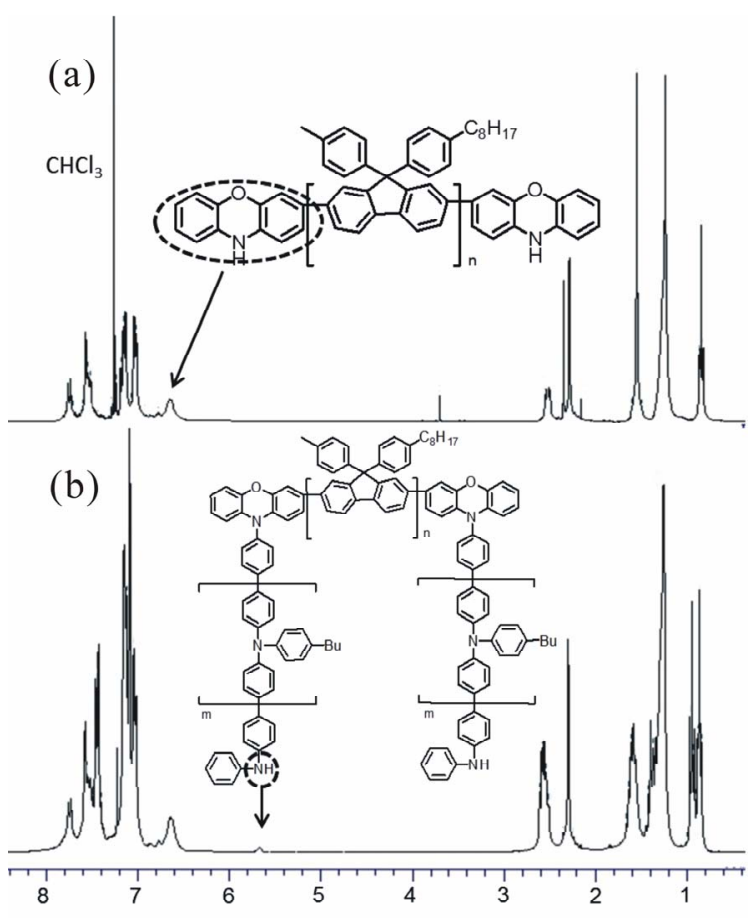

Figure 2. ${ }^{1} \mathrm{H}-\mathrm{NMR}$ of synthesized polymers measured in $\mathrm{CDCl}_{3}$ at $500 \mathrm{MHz}$ and $25^{\circ} \mathrm{C}$.

Figure 3 shows GPC profiles for PF1 and PF-PhPTAA. GPC trace of PF-Ph-PTAA was monomodal and shifted toward the higher molecular weight direction compared with PF1 homopolymer. Both NMR and GPC results suggest the successful formation of the designed block copolymer. Random copolymers, PF2s, were also synthesized by Suzuki coupling polymeriztion of $\mathbf{2}$ and $\mathbf{4}$ with $\mathbf{5}$. Table $\mathbf{1}$ lists the characteristics of prepared polymers together with the data for PF-bPTAA, which is a previously prepared block copolymer without phenoxazine units $[9,10]$.

Glass transition temperature of PF-Ph-PTAA was determined to be $148^{\circ} \mathrm{C}$ by DSC, and this value is almost the same as that of PF-b-PTAA. All the polymers were soluble in common organic solvents and readily formed thin films by a solution processing.

\subsection{Optical and Electrochemical Properties}

The optical properties of prepared polymers were investigated with UV-vis absorption and photoluminescent (PL) spectroscopies. In chloroform solutions, all polymers we examined possess similar optical properties regardless of the existence of phenoxazine moiety as shown in Table 2. In a solution state, all copolymers showed $\lambda_{\text {abs, max }}$ of $382-385 \mathrm{~nm}$, and exhibited similar PL spectra in solution state, having distinct vibronic bands at about 418 and $445 \mathrm{~nm}$ and a shoulder around $470 \mathrm{~nm}$ upon excitation at $380 \mathrm{~nm}$. As we previously reported $[9,10]$, PTAA segments show negligible contri- 


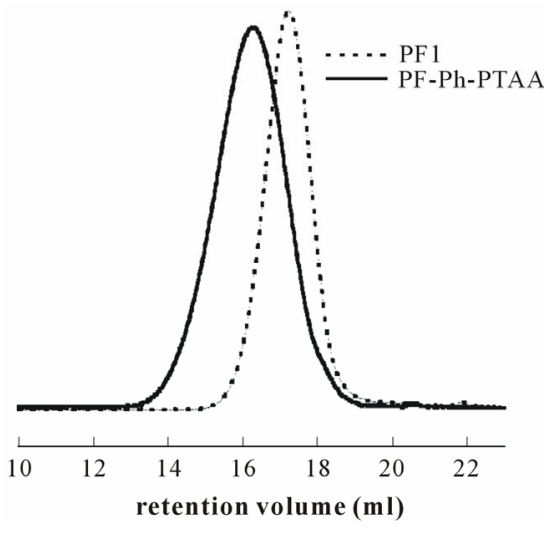

Figure 3. GPC profiles of PF1 and PF-Ph-PTAA. Effluent was monitored with UV detector $(254 \mathrm{~nm})$.

Table 1. Characteristics of synthesized polymers.

\begin{tabular}{ccccc}
\hline Polymer & Mn/10 $^{\text {3a }}$ & PDI $^{\mathbf{a}}$ & $\begin{array}{c}\text { FL } \\
\text { content }^{b} \\
\left(\mathbf{m o l}^{\mathbf{b}}\right)\end{array}$ & $\begin{array}{c}\text { Phenoxazine } \\
\text { content } \\
\text { (mol\%) }\end{array}$ \\
\hline 1PF & 4.1 & 4.0 & 78 & 22 \\
PF-Ph-PTAA & 11 & 3.4 & 44 & 13 \\
PF2 (0.2\%) & 8.0 & 2.4 & 99 & 0.2 \\
PF2 (8\%) & 25 & 3.2 & 92 & 8.0 \\
PF-b-PTAA $^{\mathrm{c}}$ & 19 & 2.4 & 57 & 0 \\
\hline
\end{tabular}

${ }^{\mathrm{a}}$ Determined by GPC; ${ }^{\mathrm{b}}$ determined by ${ }^{1} \mathrm{H}-\mathrm{NMR} ;{ }^{\mathrm{c}}$ Ref. [10].

Table 2. Optical properties of synthesized polymers

\begin{tabular}{ccccc}
\hline \multirow{2}{*}{ Polymer } & \multicolumn{2}{c}{$\lambda_{\max }(\mathbf{U V}) / \mathbf{n m}$} & \multicolumn{2}{c}{$\lambda_{\max }(\mathbf{P L})^{\mathrm{a}} / \mathbf{n m}$} \\
\cline { 2 - 5 } & Solution $^{\mathbf{b}}$ & Film & Solution $^{\mathbf{c}}$ & Film \\
\hline PF-Ph-PTAA & 382 & 380 & 419 & 426,453 \\
PF2 (0.2\%) & 385 & 380 & 419 & 426,453 \\
PF2 (8\%) & 385 & 380 & 419 & 469 \\
PF-b-PTAA & 385 & 385 & 419 & 419 \\
\hline
\end{tabular}

${ }^{\text {a }}$ Exited at $380 \mathrm{~nm} ;{ }^{\mathrm{b}} \mathrm{CHCl}_{3}$ solution, $10^{-2} \mathrm{mg} / \mathrm{mL} ;{ }^{\mathrm{c}} 10^{-4} \mathrm{mg} / \mathrm{mL}$.

bution to PL spectrum. It is also found that phenoxazine units existing at the junction point, or in the fluorene sequence of random copolymers also have almost no effects on the UV and PL spectra in the solution state.

Figure 4 shows UV-vis (a) and PL (b) spectra in a film state. Only PF2 (8\%) showed different absorption spectrum as shown in Figure 4(a). The observation of a tail over $420 \mathrm{~nm}$ is probably due to the interchain interaction between phenoxazine rich sequences. The existence of phenoxazine significantly influenced PL spectra in the film state (Figure 4(b)). PF-b-PTAA shows similar PL spectrum to that of solution indicating that interchain interaction is negligible because of the bulky substituent. However, only $0.2 \%$ of phenoxazine moiety drastically changed the PL spectrum, i.e., the spectrum showed emission peaks at 426 , and $450 \mathrm{~nm}$ with a tail. In the case of PF2 (8\%), further red shift was observed

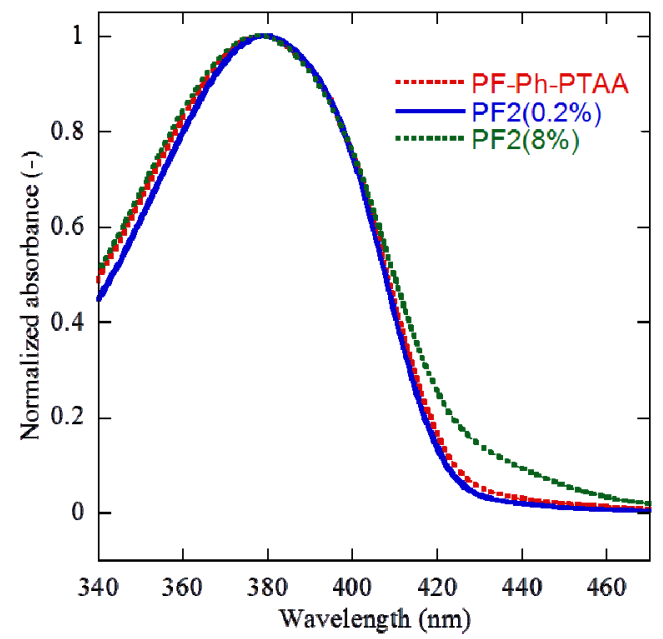

(a)

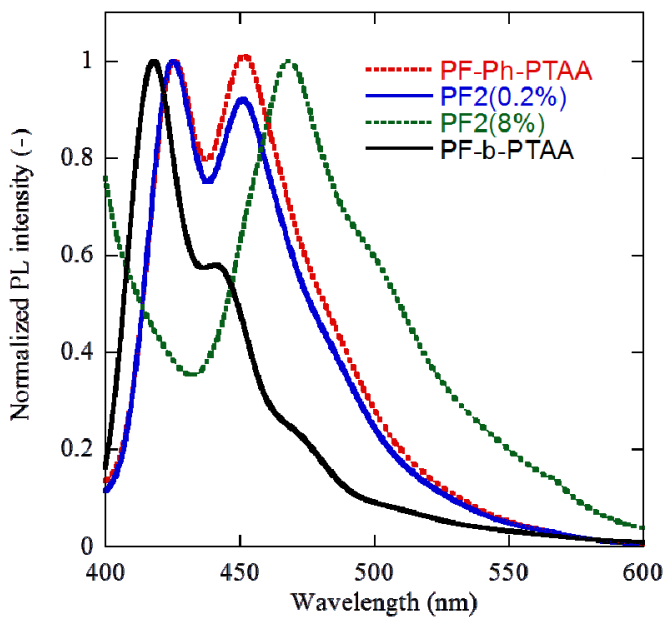

(b)

Figure 4. UV-vis (a) and PL (b) spectra of synthesized polymers in a film state. Excitation wavelength: $380 \mathbf{~ n m}$.

showing emission maximum only at $463 \mathrm{~nm}$, indicating the effective energy transfer. Although the content of phenoxazine unit in PF-Ph-PTAA was relatively high $(17 \%)$ as a result of the low molecular weight nature, it showed similar PL spectrum to that of PF2 (0.2\%). This is because phenoxazine unit is isolated in single polymer chain nevertheless the high content, and/or microphase separated structure is established in PF-Ph-PTAA film.

The electrochemical properties of the copolymers were investigated by cyclic voltammetry $(\mathrm{CV})$ with a reference electrode of $\mathrm{Ag} / \mathrm{AgCl}$. The oxidation process of $\mathrm{PF}-\mathrm{Ph}-$ PTAA started around $0.84 \mathrm{~V}$, and the reversible redox peak in the reduction process appeared at around $-0.71 \mathrm{~V}$. The energy levels of the highest occupied molecular orbital (HOMO) of the PF-Ph-PTPA was estimated from its oxidation potential according to an empirical formula, $E_{\mathrm{HOMO}}=-e\left(E_{\mathrm{ox}}+4.4\right) \mathrm{V}$. HOMO level of the block copolymer was in $-5.24 \mathrm{eV}$. The levels of the lowest unoccupied molecular orbital (LUMO) for the polymer 
were calculated with the reduction potential Ered from the empirical formula $E_{\mathrm{LUMO}}=-e\left(E_{\mathrm{red}}+4.4\right) \mathrm{V}$. LUMO level of the block copolymer was in $-3.69 \mathrm{eV}$. This result was almost consistent with that of PF-b-PTAA [10].

\subsection{EL Properties}

The performance of the EL devices based on PF-PhPTAA with the device structure of ITO/PEDOT:PSS/ polymer/LiF/Al was evaluated. The device with PF-PhPTAA blended with $20 \mathrm{wt} \%$ of PF-b-PTAA was also evaluated in order to elucidate the chemical environment where phenoxazine moiety locates. Figure 5 shows luminance vs. voltage (a), and current efficiency vs. current density (b) characteristics, respectively. Although the maximum luminance for the device based on PF-PhPTPA with $20 \mathrm{wt} \%$ of PF-b-PTPA $\left(1710 \mathrm{~cd} / \mathrm{cm}^{2}\right)$ is slightly higher than neat PF-Ph-PTPA, both devices afforded the similar current efficiency profiles. As discussed in PL section, phenoxazine unit is isolated in single polymer chain nevertheless the high content. Therefore, the environment of emitting centers in both devices is similar each other. Compared with the device based on PF-b-PTAA [10], EL performance is slightly worse. It is speculated that this is due to the low molecular weight nature of PF-Ph-PTAA, which results in the unclear microphase separation.

Figure 6 shows EL spectra for fabricated devices. Compared with the device based on PF-b-PTAA, all the devices based on phenoxazine containing polymers show ca. $50 \mathrm{~nm}$ red-shift. It is indicated that emission sites predominantly located in the vicinity of phenoxazine moiety. Because of shallow HOMO level of phenoxazine unit [14], it works as a hole trap resulting in the efficient recombination of hole and electron. Contrary to PL spectra, PF-Ph-PTAA showed similar EL spectrum to PF2 $(8 \%)$, where a tail was observed in the long wavelength region. It is possible that the interaction of excitons exists because of the local high concentration of phenoxazine moiety.

\section{Conclusion}

A block copolymer consisting of electron transporting PF and hole transporting PTAA functionalized with green emitting phenoxazine moiety at the junction point of two blocks was successfully prepared via the combination of Suzuki, and C-N coupling polymerization based on the novel molecular design of full functional polymers for the increase the efficiency in PLED. Prepared polymers exhibited similar optical properties in chloroform solutions. On the other hand, in a film state, the existence of phenoxazine unit drastically changed PL spectra. Although the content of phenoxazine unit in PF-Ph-PTAA was relatively high (13\%), it showed similar PL spectrum

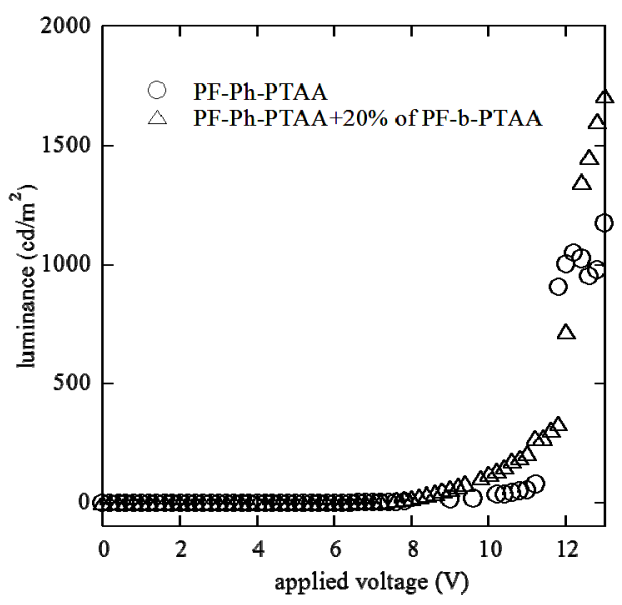

(a)

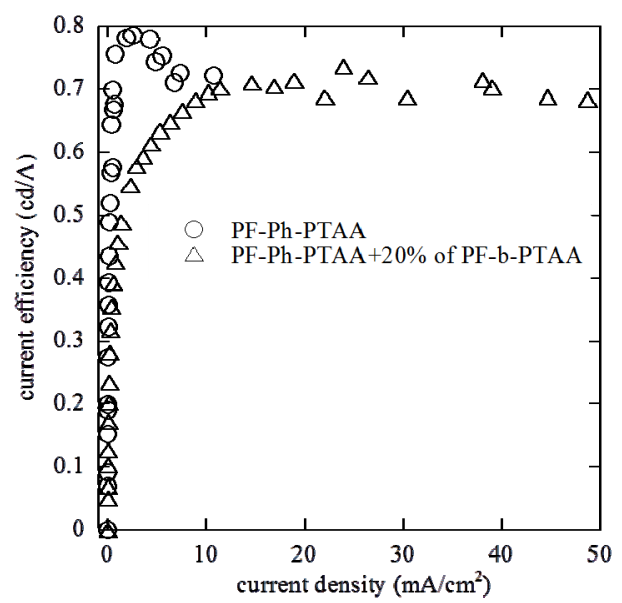

(b)

Figure 5. EL characteristics of device based on PF-PhPTAA (circle) and PF-Ph-PTAA + 20 wt $\%$ of PF-b-PTAA (triangle). (a) Luminance vs. voltage; (b) Current efficiency vs. current density.

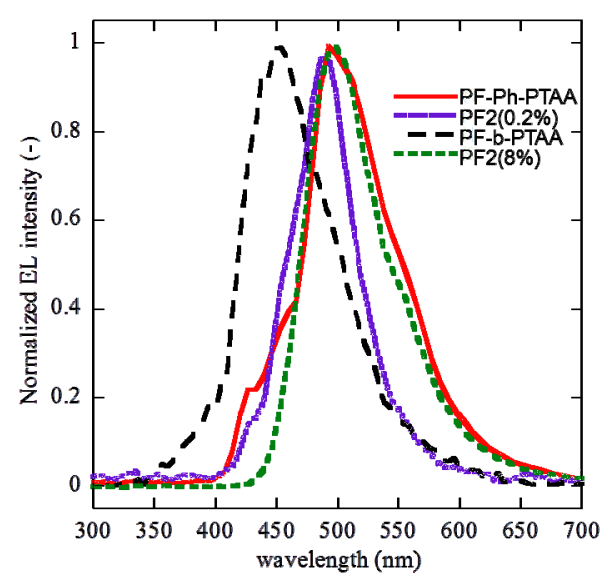

Figure 6. Electroluminescent spectra for devices based on synthesized polymers obtained at $10 \mathrm{~V}$.

to that of PF2 $(0.2 \%)$ indicating that phenoxazine unit is isolated in single polymer chain nevertheless the high 
content. EL device based on PF-Ph-PTAA showed green-emission, suggesting that emission sites predominantly located in the vicinity of phenoxazine moiety because of its shallow HOMO level. Our molecular design presented here makes it possible to control the emission site, and to afford more efficient materials for EL applications.

\section{REFERENCES}

[1] J. H. Burroughes, D. D. C. Bradley, A. R. Brown, R. N. Marks, K. Mackay, R. H. Friend, P. L. Burns and A. B. Holmes, "Light-Emitting Diodes Based on Conjugated Polymers," Nature, Vol. 347, No. 6293, 1990, pp. 539541. doi:10.1038/347539a0

[2] L. Akcelrud, "Electroluminescent Polymers," Progress in Polymer Science, Vol. 18, No. 6, 2003, pp. 875-962. doi:10.1016/S0079-6700(02)00140-5

[3] K. Tsuchiya, K. Sakaguchi, H. Kasuga, A. Kawakami, H. Taka, H. Kita and K. Ogino, "Synthesis of Charge Transporting Block Copolymers Containing 2,7-Dimethoxycarbazole Units for Light Emitting Device," Polymer, Vol. 50, No. 3, 2010, pp. 616-622. doi:10.1016/i.polymer.2009.12.024

[4] K. Tsuchiya, H. Kasuga, A. Kawakami, H. Taka, H. Kita and K. Ogino, "Synthesis of Bipolar Charge Transporting Block Copolymers and Characterization for Organic Light-Emitting Diode," Journal of Polymer Science Part A: Polymer Chemistry, Vol. 48, No. 7, 2010, pp. 1461-1468. doi:10.1002/pola.23853

[5] K. Tsuchiya, K. Sakaguchi, A. Kawakami, H. Taka, H. Kita, T. Shimomura and K. Ogino, "Charge Transporting Block Copolymer for Morphological Control in Light Emitting Device Based on Polymer Blends," Synthetic Metals, Vol. 160, No. 15-16, 2010, pp. 1679-1682. doi:10.1016/j.synthmet.2010.05.040

[6] J. K. Kim, S. Y. Yang, Y. Lee and Y. Kim, "Functional Nanomaterials Based on Block Copolymer Self-Assembly," Progress in Polymer Science, Vol. 35, No. 11, 2010, pp. 1325-1349. doi:10.1016/j.progpolymsci.2010.06.002

[7] L. Deng, P. T. Furuta, S. Garon, J. Li, D. Kavulak, M. E. Thompson and J. M. J. Fréchet, "Living Radical Polymerization of Bipolar Transport Materials for Highly Efficient Light Emitting Diodes," Chemistry of Materials,
Vol. 18, No. 2, 2006, pp. 386-395. doi:10.1021/cm051922+

[8] B. Ma, B. J. Kim, L. Deng, D. A. Poulsen, M. E. Thompson and J. M. J. Fréchet, "Bipolar Copolymers as Host for Electroluminescent Devices: Effects of Molecular Structure on Film Morphology and Device Performance," Macromolecules, Vol. 40, No. 23, 2007, pp. 8156-8161. doi:10.1021/ma0715526

[9] Y. Tan, Z. Gu, K. Tsuchiya and K. Ogino, "Synthesis and Luminescent Properties of Block copolymers Based on Polyfluorene and Polytriphenylamine," Polymer, Vol. 53, No. 7, 2012, pp. 1444-1452. doi:10.1016/j.polymer.2012.02.021

[10] Y. Tan, K. Tsuchiya and K. Ogino, "Synthesis of Polyfluorene Block Copolymers and Effect of Side Chain Group on Electroluminescent Device Performance," Chemistry Letters, Vol. 41, No. 3, 2012, pp. 257-259. doi:10.1246/c1.2012.257

[11] A. Nowakowska-Oleksy, J. Sołoducho and J. Cabaj, "Phenoxazine Based Units-Synthesis, Photophysics and Electrochemistry," Journal of Fluorescence, Vol. 21, No. 1, 2011, pp. 169-178. doi:10.1007/s10895-010-0701-6

[12] H. Tanaka, K. Shizu, H. Miyazaki and C. Adachi, "Efficient Green Thermally Activated Delayed Fluorescence (TADF) from a Phenoxazine-Triphenyltriazine (PXZTRZ) Derivative," Chemical Communications, Vol. 48, No. 93, 2012, pp. 11392-11394. doi:10.1039/c2cc36237f

[13] J.-H Park, N. S. Cho, Y. K. Jung, H.-J. Cho, H.-K. Shim, H. Kim and Y. S. Lee, "Polymeric Light Emitting Properties and Structural Relationships of Fluorene-Based Conjugated Copolymers Containing Various Hole Transporting Derivatives," Organic Electronics, Vol. 8, No. 2-3, 2007, pp. 272-285. doi:10.1016/j.orgel.2006.08.002

[14] Y. Pei, M. Otake, M. Vacha and H. Sato, "Synthesis and Characterization of a Novel Electroluminescent Polymer Based on Phenoxazine and Fluorene Derivatives," React. Funct. Polym., Vol. 67, No. 11, 2007, pp. 1211-1217. doi:10.1016/j.reactfunctpolym.2007.07.011

[15] K. Tsuchiya, T. Shimomura and K. Ogino, "Preparation of Diblock Copolymer Based on Poly(4-n-butyltriphenyl amine) via Palladium Coupling Polymerization," Polymer, Vol. 50, No. 1, 2009, pp. 95-101. doi:10.1016/j.polymer.2008.10.057 